\title{
Suture Suspensions for Lifting or Volume Augmentation in Face and Body
} Nikolay P Serdev*

Honorary Professor, Director of the International University Program in Aesthetic/Cosmetic Surgery at the New Bulgarian University, Head, Medical Centre "Aesthetic Surgery, Aesthetic Medicine, Sofia, Bulgaria

\begin{abstract}
Scarless closed approach suture liftings present skeletal fixation with skin punctures without incisions as a first alternative to classic excision lifts. The author started the anatomy study, instrument creation and thread selection in 1990 and the whole topographic anatomy, instrumentarium and technique understanding of this new method was ready in 1993. Needle preparation and selection of threads was experimental. Stretch, elasticity and cut through tests were performed for selecting threads. Thread long term absorption is crucial in this method. 54 patients were operated in 1993-1994 to correct early ptosis and flabbiness in areas of face and body and the results were published. Author's contribution is that his closed approach suture techniques lift SMAS and fascias without traditional incisions. Operations are ambulatory with excellent results, reported by the patients. The trauma is minimal and the follow-up period is no longer than a few hours to 3 days with fast, sometimes immediate return to work and social life. There are no visible scars; the needle perforations on the skin disappear within 2-3 days.
\end{abstract}

Keywords: Suture lifting; Brow lift; SMAS

\section{Technique and Anatomical Fixations}

Operations are ambulatory without hospital stay. The techniques consist of passing closed sutures, by needle perforations only, to lift movable fascias and fix them to non-movable skeletal structures in several facial and body areas [1-23].

The author performs the following scarless closed approach suture lifts:

\section{In face areas}

- Ambulatory temporal and supra-temporal SMAS Lift; (Figures 1-3).

- Brow lift, (Figures 4-6).

- Lateral canthus lifting.

- Glabella muscle ligation.

- Mid-face SMAS suture lift, (Figures 7 and 8).

- Cheekbone SMAS lift and volume creation, (Figures 9 and 10).

- Lower SMAS face and neck lift, (Figures 11-13).
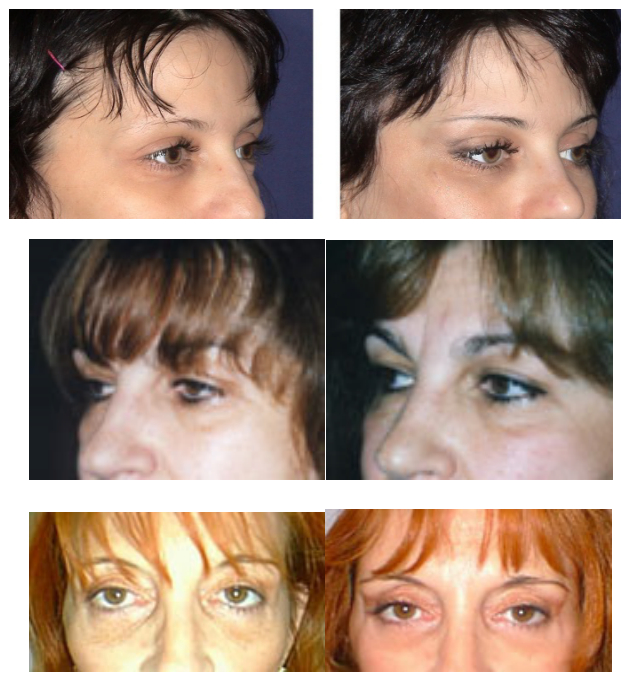

Figures 1,2: Temporal (upper SMAS to upper temporal line and temporal fascia) and Figure 3. supra-temporal (upper SMAS to upper temporal line) suture SMAS lifts.
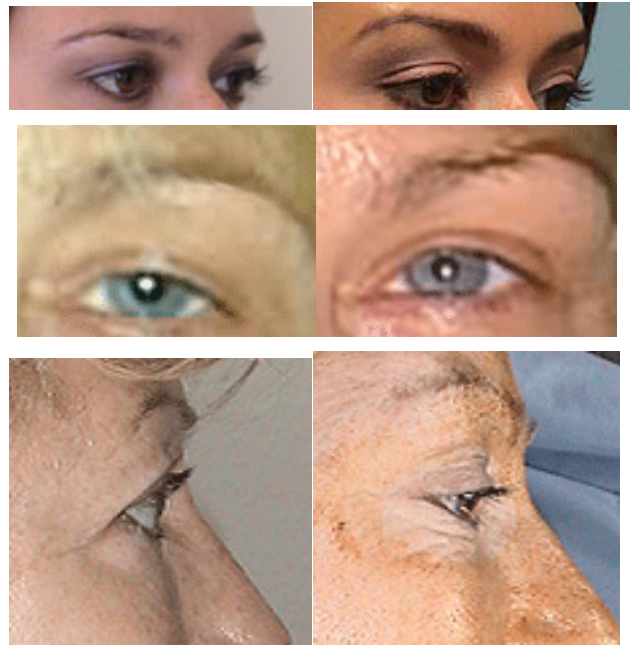

Figures 4-6: Scarless brow suture lifts (orbito-cutaneous brow fascia discovered by the author to upper temporal line periosteum at $1,5 \mathrm{~cm}$ or at hair line).

- Chin enhancement, form and position correction by suture; (Figures 14-16).

- Nasal tip refinement; nasal tip rotation; nasal alar base narrowing; (Figure 17).

- Scarless Serdev suture ${ }^{\bullet}$ method in prominent ears, (Figures 18-20).

- Dimple formation in chin and smiling point etc.

In body areas

- Scarless breast lift by suture, (Figure 21)

*Corresponding author: Nikolay P Serdev, Honorary Professor, New Bulgarian University, Director, Medical Centre "Aesthetic Surgery, Aesthetic Medicine", Sofia, Bulgaria, Tel: +359885719696; Fax:+35929515668; E-mail: serdev@gmail.com

Received June 20, 2013; Accepted July 17, 2013; Published July 24, 2013

Citation: Serdev NP (2013) Suture Suspensions for Lifting or Volume Augmentation in Face and Body. Anaplastology 2: 115. doi: 10.4172/2161-1173.1000115

Copyright: (c) 2013 Serdev NP. This is an open-access article distributed under the terms of the Creative Commons Attribution License, which permits unrestricted use, distribution, and reproduction in any medium, provided the original author and source are credited. 
Citation: Serdev NP (2013) Suture Suspensions for Lifting or Volume Augmentation in Face and Body. Anaplastology 2: 115. doi: 10.4172/21611173.1000115
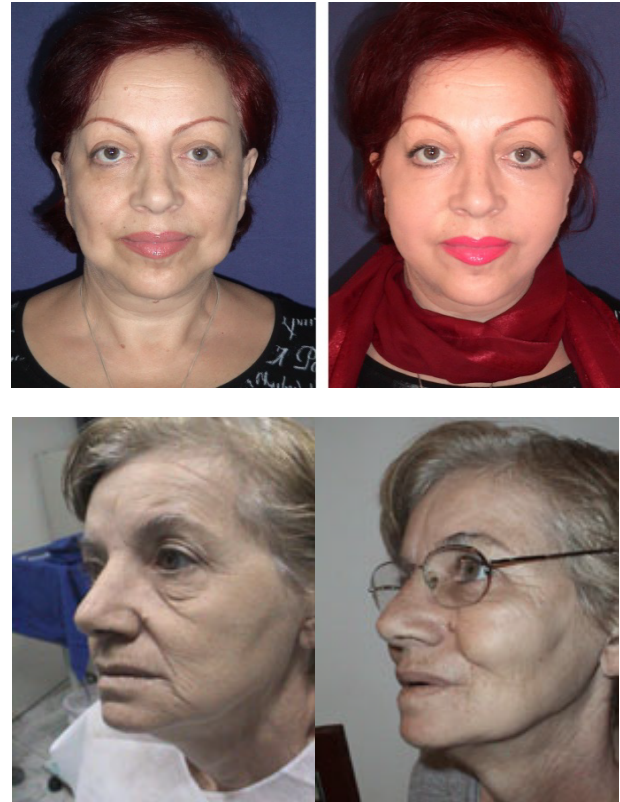

Figures 7,8: Mid-face suture lifts (SMAS zygomatic extension to upper tempora line periosteum or to temporo-parietal tendon).

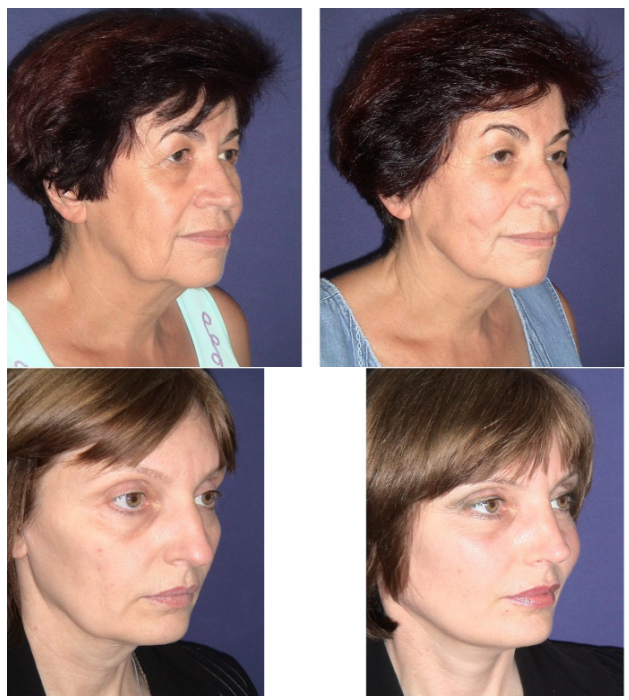

Figures 9,10: Cheekbone lifts (Bichat fat pad fascial tube to zygomaperiosteum) and augmentation using own patient tissue without implants.

- Scarless buttock lift by suture, (Figures 22-24)

- Scarless Serdev Suture ${ }^{\bullet}$ to reposition breast implants in symmastia and false position

- Abdominal flaccidity tightening, (Figure 25)

- Inner thigh lift (Figure 26)

\section{Results}

Results in all patients were more than satisfactory. They were mostly amazed by the immediate beautification, rejuvenation and the great difference before and after without scars and with nearly immediate return to work and social meetings.

The cosmetic results were evaluated with preoperative and
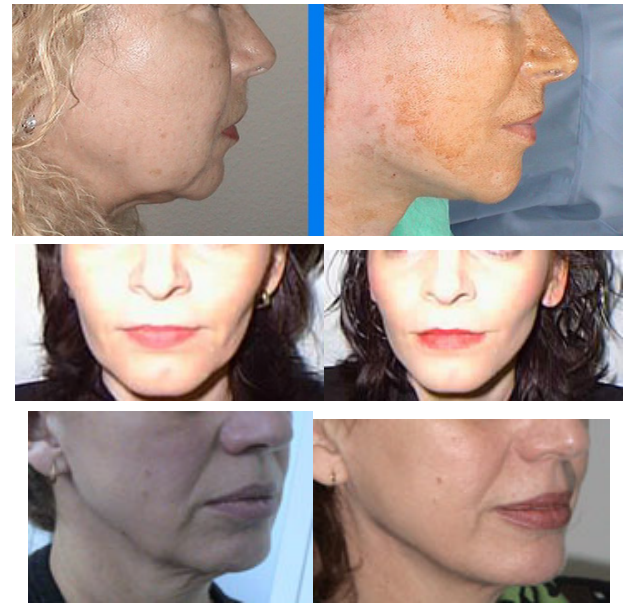

Figures 11-13: Lower SMAS-platysma face and neck lifts (platysma fixation to mastoid).
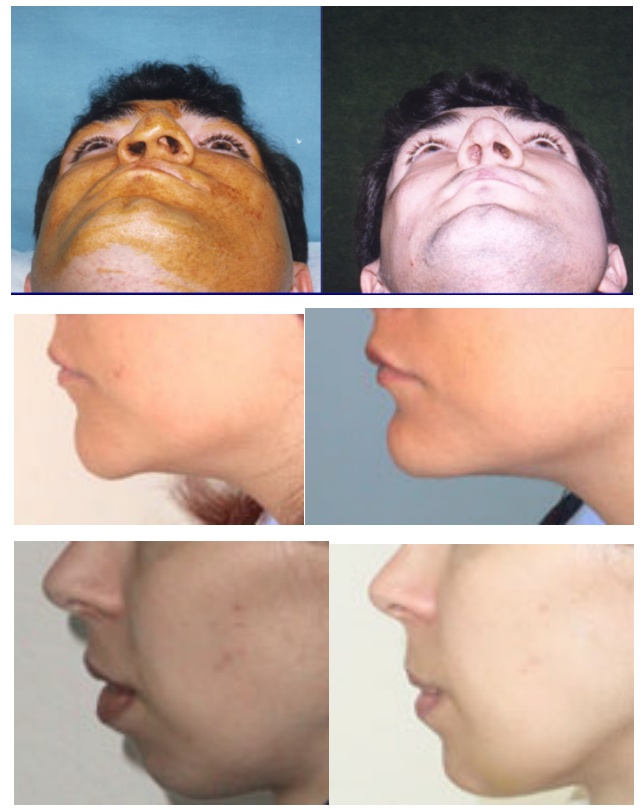

Figures 14-16: Chin enhancements, form and position corrections with or without fixation to the menton.

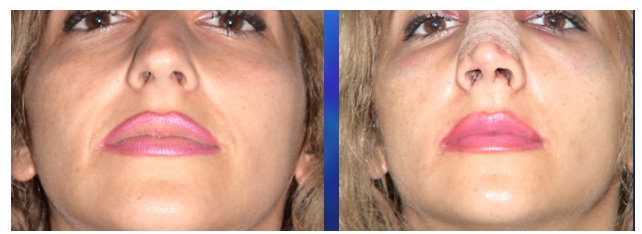

Figure 17: Sutures in rhinoplasty: for tip rotation (medial crura of greater alar cartilages to nasal bone periosteum), tip refinement (suturing together all 4 crura of both greater alar cartilages at the dom), allar base narrowing (suturing the alar base incl. accessory alar cartilages).

postoperative photographs and by patient satisfaction. Patients were satisfied with the results and all of them considered their results as excellent or good.

No other complications were observed, except some local infections in one of the perforation points in the early postop period, treated in a 
Citation: Serdev NP (2013) Suture Suspensions for Lifting or Volume Augmentation in Face and Body. Anaplastology 2: 115. doi: 10.4172/21611173.1000115
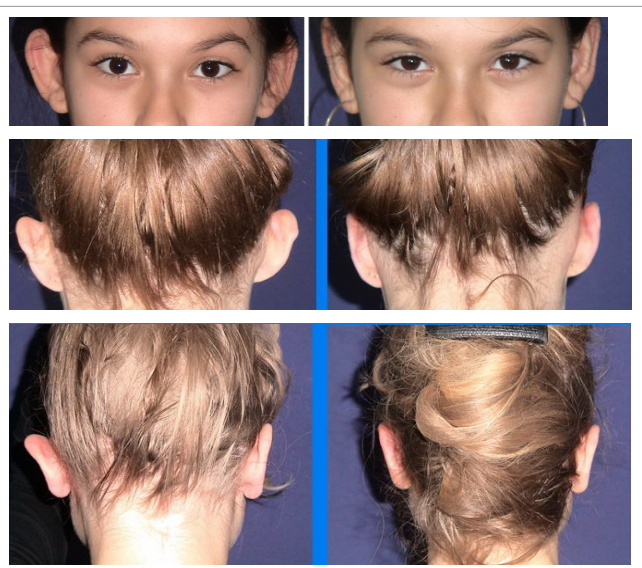

Figures 18-20: Otoplasties in prominent ears (closed approach perihondrium suture to obtain the antihelix fold) etc.

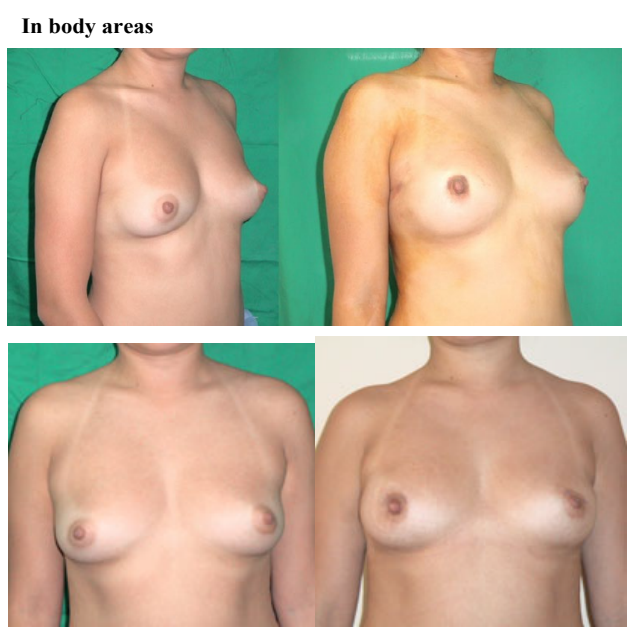

Figure 21: Scarless breast lifts (fixation of breast fascia to clavicle and/or pectoralis major tendon).

day or two. No nerve damage by the suture was observed. Cheekbone sutures were removed in one Asian patient due to patient's aesthetic considerations.

\section{Discussion}

Nowadays these methods are preferable in the modern society where business does not allow long time of absence. Closed approach suture methods have shown priority over classic excision liftings requiring hours of operation, marked trauma, long postoperative swelling and downtime.

Serdev suture ${ }^{\bullet}$ liftings require about $15 \mathrm{~min}$ of operating time per side, no blood loss or transfusions, no stay at the clinic, no nursing care and not more than a day or two off work. Results are immediate with no downtime. Most of the patients work next day after operation that is most appreciated by the patients.

\section{Conclusion}

We can recommend the closed suture methods for young and mid age patients with congenital problems in aesthetic appearance and in cases of initial or moderate flabbiness and tissue sagging.
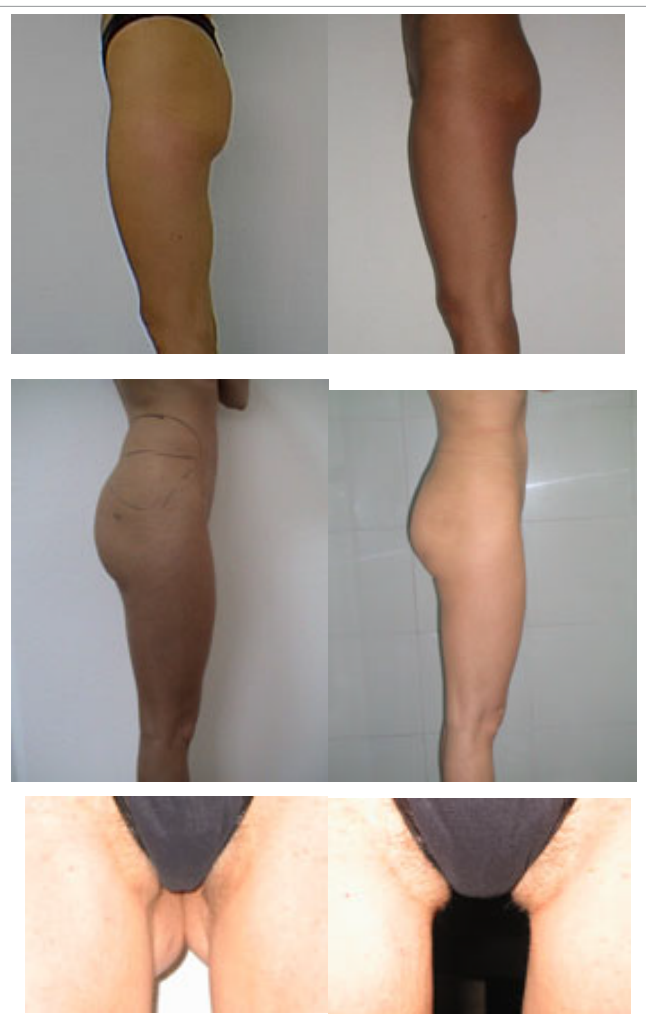

Figures 22-24: Buttock lifts (fixation of the fibrous tissue to the sacro-cutaneus fascia, found by the author).

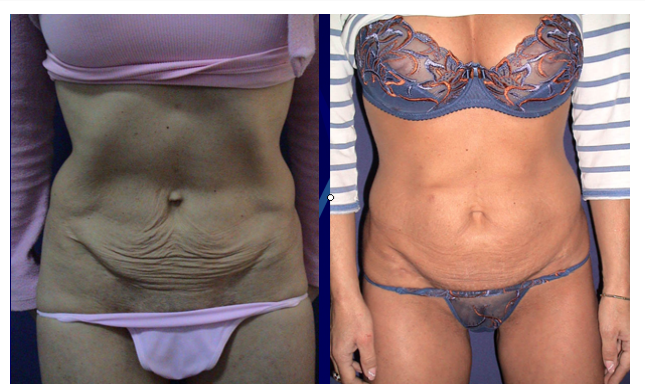

Figure 25: Abdominal flaccidity tightening (lineaalba shortening, superficial fascia to costal line, spinailiaca superior anterior).

\section{Contribution}

Serdev Suture ${ }^{\infty}$ Techniques are the first lifting method to replace scarring classic excision liftings as a complete method for scarless closed approach liftings on total face and body where movable fascias (holding skin by trabecular system) can be lifted and fixed to nonmovable periosteum, tendons and fascias.

\section{Author's suture techniques contributions}

- A new method for closed approach face and body lifting - a new alternative to classic excision lifts

- Scarless, skin punctures only - no incisions and excisions

- Mini-invasive, no downtime

- Beautification and rejuvenation

- When needed tissue augmentation is performed using patient's tissue - a new alternative without implants 
Citation: Serdev NP (2013) Suture Suspensions for Lifting or Volume Augmentation in Face and Body. Anaplastology 2: 115. doi: 10.4172/21611173.1000115

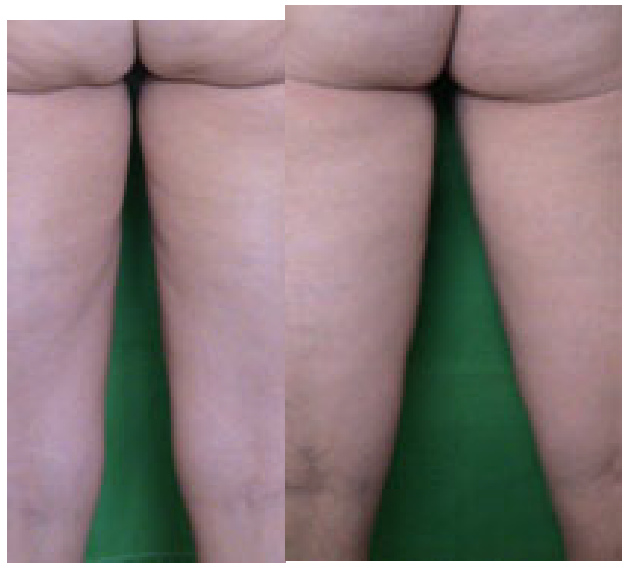

Figure 26: Inner thigh lift.

- Can be used in cosmetic, aesthetic and plastic-reconstructive surgery

Downtime is shortened from weeks to only a few days. No bruising, no danger of hematoma formation, no nerve damage, no scars.

The suture methods became possible after creating special curved semi-elastic, semi-blunt needles.

Serdev Needles were specially designed and developed for best use and have the following qualities:

- Elastic curve (the curve can not be changed when using pressure)

- Smooth surface (does not cut periosteum)

- Cone semi-blunt tip (trauma is minimized)

- Length and thickness depending on application from 50 to $250 \mathrm{~mm}$

Surgical threads were selected and best results were obtained with the Bulgarian policaproamide sutures Polycon, which are ensuring semi-elastic fixation of movable to non-movable tissue, they do not cut through the tissue like other available non elastic surgical treads, the author has tried on experiment. Preferred thread qualities were - short elasticity, absorbable within two years - after final fibrosis formation, anti-microbial action. The author's tests have shown that only Polycon ensures these qualities. Polycon offers thread thickness depending on application $-3 / 0,0,2,4,6,8$.

\section{References}

1. Serdev NP (1993) Forehead Subperiosteal Masklift in Combination with Mclndoe FaceliftTechnique and Profile Correction. The 7th IPRAS Congress European Section, Berlin,Germany, June 2-5.

2. Serdev NP (1994) Suture Suspensions For Lifting Or Volume Augmentation InFace And Body (English version). Int J Aesth Cosm 1: 2561-2568.

3. Serdev NP (1994) Accessories to Face Lifting. II International Symposium of Updating on SkinAesthetic, Sao Paolo, Brazil, 6-8 May.

4. Serdev NP (1994) Temporal SMAS lift without skin excision. AAARS Annual Meeting, New Orleans, USA, October 5-9.

5. Serdev NP (1999) Temporal SMAS Lifting of the Face. Life Surgery Workshop. Unidad Medica Clinica Del Country, Bogota D.C., Colombia, November 8-10.

6. Serdev NP (1999) SMAS lifting of the face by minimal incisions - the Serdev
Technique.42 Life Surgery Workshop sponsored by International Academy of Cosmetic surgery andthe Balkan Academy of Cosmetic Surgery, held at the Krilig Clinic in Caracas,Venezuela, November 12-18.

7. SerdevNP (1999) Principles of Face Beautification, ler Congresso Internacional de CirurgiaCosmetica, Buenos Ares Argentina.

8. Serdev NP (2000) Temporal smas lift, lecture and life demonstration. 1st World Congressof Cosmetic Surgery with Life Demonstrations, Edsa Shangri-La Manila and QuezonCity Medical Center, February 25-27.

9. Serdev NP (1999) Live Surgery Workshop, SMAS lifting of the face by minimal incision -Brow, Temporal, Medial, Lower - the Serdev Technique. The International Academy ofAesthetic Surgery and Aesthetic Medicine, The Krulig Clinic, Caracas, Venezuela, Nov.

10. Serdev NP (2000) Temporal SMAS Lifting of the Face, Combined with Liposuction and ChinAugmentation Using Suture. Life Surgery Workshop, Tel Aviv, Israel, April 20-24.

11. Serdev NP (2000) Principles of face beautification, The 3-rd World Congress of ISAS, Tokyo, April 8-10.

12. Serdev NP (2000) Lifting del SMAS con Una Pequenna Incision Temporal, VIIlas Journadas Mediterraneas de Confrontaciones Terapeuticasen Medicina y Cirurgia Cosmetica, Sitges, Barcelona, March 16-19.

13. Serdev NP (2000) Scarless Brow Lift Using A Special Suture. Presentations - 3rd World 14.

14. Serdev NP (2010) Auriculoplasty for beautification - a post-congress workshop, Asia PacificCraniofacial Association.

15. Serdev NP (2002) Principles of Face Beautification, Xlas Jornadas Mediterraneas DeConfrontaciones Terapeuticas En Medicina y Cirugia Cosmetica. Int J Cosm Surg 2.

16. Serdev NP (2006) Tratamento De Flacides Cutanea Abdominal Com Filos Elasticos Serdev /Scarless Serdev Suture Methods For Abdominal Skin Flaccidity, 12 CongressoBrasiliero Medicina Estetica - 15 - 18 June 2005, Salvador. Int J Cosm Surg 6: 1-25.

17. Serdev NP (2009) Scarless Serdev Suture Method In Prominent Ears (Bulgarian), OriginalPapers. Int J Aesth Cosm 9: 1-9.

18. Serdev NP (2009) Breast Lift: My Methods Presentations from the Congress "VI Sharing withthe Experts" - San Salvador. Int J Cosm Surg 9: 1-39.

19. Serdev NP (2009) Serdev Suture Techniques Breast Lift Original Papers. Int $J$ Cosm Surg 9: 1-3.

20. Serdev NP (2010) Minimally Invasive Author Technique For Breast Lift Withou Scars UsingSutures. Int J Cosm Surg 10: 1.

21. Serdev NP (2011) Eyebrow lifting by suture (from "Serdev Sutures. Scarless face and bodyliftings"). Int J Aesth Cosm 11: 1-2

22. Serdev NP (2012) Brow lifting to the upper temporal line $1.5 \mathrm{~cm}$. Int J Aesth Cosm 12: 1-62.

23. SerdevNP (2012) Brow lifting with fixation to the upper temporal line at the hairline. Int JAesth Cosm12: 3-6. 